\title{
Virtual screening for novel inhibitors of human Histone Deacetylase 6: Promising new leads for Oral Squamous Cell Carcinoma
}

\author{
Sandhya Vijayasarathy ${ }^{1 *}$, Jhinuk Chatterjee ${ }^{2}$ \\ ${ }^{1}$ Department of Biotechnology, PES Institute of Technology, Bangalore 560085, India. \\ ${ }^{2}$ Department of Biotechnology, PES University, Bangalore 560085, India.
}

\section{ARTICLE INFO \\ Article history: \\ Received on: March 15, 2021 \\ Accepted on: June 25, 2021 \\ Available online: November 10, 2021}

Key words:

Oral Squamous Cell Carcinoma,

Histone Deacetylase inhibitors,

Virtual Screening, Molecular

Docking, Cell line study

\begin{tabular}{l}
\hline ABSTRACT \\
\hline Over $90 \%$ of Oral Cancers are Oral Squamous Cell Carcinomas (OSCCs). Despite having advanced treatment \\
modalities, there is no significant improvement in the survival rate of Oral Cancer patients over the years. \\
Thus, there arises a need for the identification of new drug targets besides development of new and effective \\
drugs for this disease. Since Histone Deacetylase 6 (HDAC6), a class IIB member of HDAC family, is known \\
to be upregulated in this disease in addition to being associated with tumor growth, it can be considered as a \\
promising drug target for this disease. In this study, a structure-based virtual screening strategy was used to \\
screen a library of 1,539 natural compounds from Naturally Occurring Plant-based Anti-cancerous Compound- \\
Activity-Target (NPACT) database. Upon filtering and docking, top 30 hits were identified and two of them, \\
namely Camptothecin and Diosgenin, were tested experimentally on OSCCs cell lines for anti-proliferative \\
effects. Both of these compounds exhibited inhibitory activity against Oral Cancer cells, therefore suggesting \\
that they can be potential HDAC6 inhibitors, which can further serve as promising leads for OSCCs.
\end{tabular}

\section{INTRODUCTION}

Combinatorial chemistry and high-throughput screening are time-consuming and expensive methods for the synthesis of new compounds. The most suitable alternative is screening small molecule databases for novel compounds. Virtual screening involves computationally screening of huge libraries of chemicals for compounds that target counterparts of known structure, and experimentally test those that bind well. Virtual screening, or in silico screening, forms a new approach garnering high interest in the pharmaceutical industry as an easy, productive and costeffective technology in pursuit of novel lead compounds for a specific target which is of utmost importance to the initial phase of drug discovery $[1,2]$.

Structure-based virtual screening is based on the binding mode prediction along with the analysis of binding affinities of each compound by protein-ligand docking. This approach becomes tedious when the data set is huge. So, an alternative approach

*Corresponding Author

Sandhya Vijayasarathy, Department of Biotechnology, PES Institute of Technology, Bangalore 560085, India.E-mail: sndbt123@gmail.com is to filter out unpromising compounds before docking. In this way, the data set can be restricted to drug-like compounds only. This filtering is based on appropriate property and sub-structural features. This method is quite effective in decreasing the data set used for docking to the order of $10^{3}-10^{4}$ compounds from a huge library of compounds $[3,4]$.

Oral Cancer is a sub-division of head-and-neck squamous cell carcinoma [5]. Oral Cancer contributes to more than $30 \%$ of all cancers, thus being one of the top three cancers in the Indian subcontinent. The annual incidence of Oral Cancer is $\sim 300,000$ cases, of which $62 \%$ are observed in developing nations. As many as 145,000 deaths occur globally and 50,000 deaths occur in India annually [6]. Majority of Oral Cancers are Oral Squamous Cell Carcinomas (OSCCs). It is the malignancy of the oral cavity [7]. Risk factors include chronic tobacco usage, excessive alcohol consumption, chronic inflammations, infection by human papilloma virus, betel quid chewing, and genetic predisposition [8]. OSCC mainly includes cancer of the tongue, lip, palate, gingiva, buccal mucosa, and floor of the mouth. OSCC is diagnosed often during the later stage of the disease as patients fail to seek medical help at the right time, either for the reason that they fail to realize 
the significance of early symptoms, or they might show ignorance toward the health implications $[9,10]$.

Early detection of Oral Cancer could be one of the most effective ways to decrease the high mortality rate of this ailment [11]. Over the years, although Oral Cancer treatment modalities have advanced, the survival rate of Oral Cancer patients is yet to improve significantly $[12,13]$. The overall survival rate declines as the cancer stage rises from $75 \%$ to $90 \%$ for Stage I in contrast to $10 \%-22 \%$ for Stage IV [14]. This marks the necessity for the development of new and potential drugs in addition to finding new drug targets for this disease.

Over 3,000 plants globally are known to possess anti-cancer properties. The incidence of the use of plant-derived products for the treatment of cancer ranges from $10 \%$ to $40 \%$, reaching $50 \%$ among Asiatic patients [15]. In traditional medicine, terpenoids, flavonoids, tannins, alkaloids, phenols, and quinones have been used to treat various infections and diseases as they are rich in secondary metabolites [16-18].

Histone deacetylases (HDACs) forms one of the promising classes of anti-cancer drug targets as they are capable of reversing abnormal epigenetic states related to cancer. Cell-cycle arrest, apoptosis, and differentiation are some of the cell type-specific effects that they elicit [19]. HDAC6, a member of the HDAC family, is known to be upregulated in OSCC and it increases during the advanced stages of the cancer. Overexpression of HDAC6 is associated with tumor growth. Thus, selective inhibition of HDAC6 could be a promising method for the treatment of oral cancer and has been, therefore, considered for this study.

In this study, virtual screening along with docking was employed to screen a library of 1,539 plant-based natural compounds. Many hits were obtained, of which several were novel inhibitors of HDAC6 and potential leads for oral cancer. Furthermore, two of the procurable hits were tested for its inhibition activity in vitro by 3-(4,5-Dimethylthiazol-2-yl)-2,5-Diphenyltetrazolium Bromide (MTT) assay to confirm its anti-cancer effects on the Squamous Carcinoma Cell line (SCC-9).

\section{MATERIALS AND METHODS}

\subsection{Homology Modeling}

Since the X-ray structure of a complete sequence of 1,215 residues for human HDAC6 was not available during the time of study in 2016, a 3D structure of the protein was predicted via homology modeling from its primary sequence. The amino acid sequence of human HDAC6, with accession no. AAH69243.1, was retrieved in FASTA file format from the NCBI protein database [20]. This was submitted to the SWISS-MODEL server [21]. From the predicted result, the top model with a better QMEAN (Qualitative Model Energy ANalysis) was selected and was further validated by Ramachandran plot and Verify-3D [22].

\subsection{Virtual Screening}

Identification of potential lead compounds was achieved by carrying out virtual screening of phytochemicals from the Naturally Occurring Plant-based Anti-cancerous Compound-
Activity-Target (NPACT) database [23]. A total of 1,539 anticancer plant-based natural compounds belonging to categories of terpenoids, flavonoids, alkaloids, polyketides, lignans, polycyclic aromatic natural compounds, steroids, simple aromatic natural compounds, saponins, carbohydrates, organic chemicals, oxygen heterocycles, benzopyranoids, benzofuranoids, aliphatic natural compounds, amino acids, peptides, polypyrroles, and tannins were collected. Compounds were screened to fit using Lipinski guidelines for drug-likeness; partition coefficient $\log \mathrm{P}$ was $\leq 5$, hydrogen bond donors were $\leq 5$, hydrogen bond acceptors were $\leq 10$, besides molecular weight that was $\leq 500$ [24]. Finally, 676 compounds were subjected to docking.

\subsection{Molecular Docking}

Molecular docking is a target-based drug design method [25]. It was carried out using the AutoDock Vina [26] module available in PyRx 0.8 software [27]. Both the receptor and ligands were prepared and saved in .pdbqt format. During the docking process, the receptor was considered rigid and the ligand flexible. Docking grid size was enlarged to accommodate the entire protein inside the grid box with dimensions of 53,65 , and $49 \mathrm{~A}^{\circ}(X, Y$, and $Z$ ). Furthermore, Lamarckian genetic algorithm was used for searching best possible conformers. A maximum of 10 conformers were generated for each compound during the docking process.

\subsection{Short Listing of Potential Leads}

After docking, 10 conformers were produced for each compound. On the basis of the least binding affinity, the best pose was selected. These docked structures were visualized in PyMOL software (the PyMOL Molecular Graphics System, Version 1.8, Schrödinger, Inc) for studying the residue-ligand interactions [28]. The highest scoring compounds were determined from the docking result and a focused library was formed, which were considered for testing on cell lines, out of which Camptothecin and Diosgenin were chosen as they were procurable. The binding energy of all the compounds was compared with a reference drug molecule Vorinostat (IUPAC: N'-hydroxy-Nphenyloctanediamide), which is a Food and Drug Administration approved HDAC inhibitor.

\subsection{Chemicals and Reagents for Experimental Validation}

MTT powder (the solution was filtered through a $0.2 \mu \mathrm{m}$ filter. It was then stored at $2^{\circ} \mathrm{C}-8^{\circ} \mathrm{C}$ ), dimethyl sulfoxide (DMSO), phosphate buffered saline (PBS), $-125 \mathrm{mM} \mathrm{NaCl}$ in $10 \mathrm{mM}$ sodium phosphate buffer, $\mathrm{CO}_{2}$ incubator, Tecan Plate reader were used.

\subsection{Cell Lines and Culture Medium}

The OSCC cell line derived from human tongue (SCC-9) was obtained from American Type Culture Collection for the study. Cells were cultured in Dulbecco's Modified Eagle's Medium (DMEM) supplemented with 10\% Fetal Bovine Serum, penicillin $(100 \mathrm{U} / \mathrm{ml})$, and streptomycin $(100 \mu \mathrm{g} / \mathrm{ml})$. Cells were incubated in a humidified atmosphere of $5 \% \mathrm{CO}_{2}$ at $37^{\circ} \mathrm{C}$. Cells were dissociated with TPVG solution ( $0.2 \%$ trypsin, $0.02 \%$ EDTA, and $0.05 \%$ glucose in PBS). Cell viability was checked. Finally, 


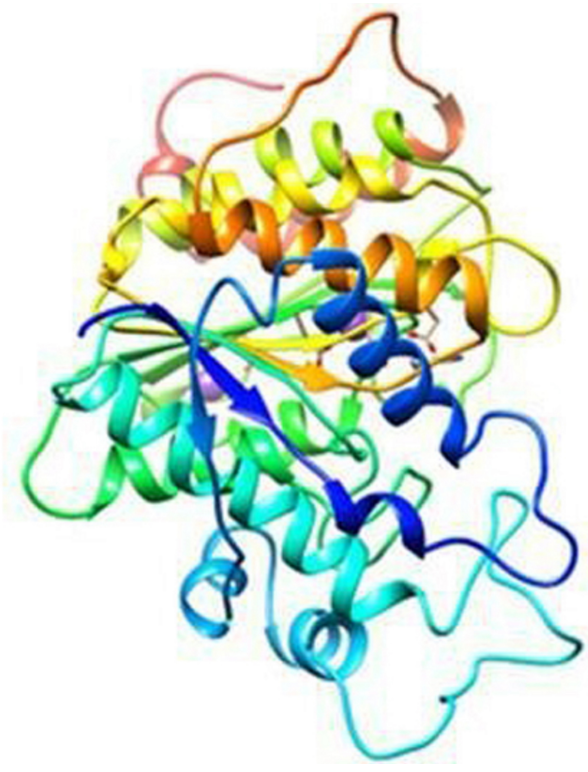

Figure 1. Homology modeled 3D structure of human HDAC6.

50,000 cells/well of SCC-9 were seeded in a 96-well plate and incubated for 24 hours at $37^{\circ} \mathrm{C}, 5 \% \mathrm{CO}_{2}$ incubator.

\subsection{MTT Assay}

$5.0 \times 10^{5}$ cells of SCC-9 were seeded in 96-well plates with DMEM. Camptothecin was tested at different concentrations of 0 ,
$15,31,62,125,250,500$, and $100 \mu \mathrm{g} / \mathrm{ml}$ in DMEM media. This was followed by incubation for 24 hours in a $\mathrm{CO}_{2}$ incubator at $37^{\circ} \mathrm{C}$. After incubation, the media was removed from the wells and $100 \mu \mathrm{l}$ of the MTT reagent was added in each well and incubated again for 4 hours. Then, MTT reagent was removed and $100 \mu \mathrm{l}$ DMSO was added to each well and gently shaken. Furthermore, absorbance or optical density (OD) was measured at $590 \mathrm{~nm}$ using a SpectraFluor Tecan plate reader and Camptothecin-treated cells were compared to untreated cells $[29,30]$.

\subsection{Statistical Analysis}

The percentage growth inhibition was computed using the following formula:

$$
\begin{aligned}
\% \text { Inhibition }= & \text { OD of Control }- \text { OD of Sample } / \\
& \text { OD of Control }) \times 100
\end{aligned}
$$

The concentration of Camptothecin needed to inhibit cell growth by $50 \%\left(\mathrm{IC}_{50}\right)$ values is generated from the dose-response curve. $\mathrm{IC}_{50}$ values were derived from a nonlinear regression analysis based on sigmoid dose-response curve and visualized using GraphPad Prism version 5.0 software.

\section{RESULTS AND DISCUSSION}

\subsection{Homology Modeling}

The structure of human HDAC6 was predicted using homology modeling by submitting the FASTA sequence of the protein with accession no. AAH69243.1 to the SWISS-MODEL server. From

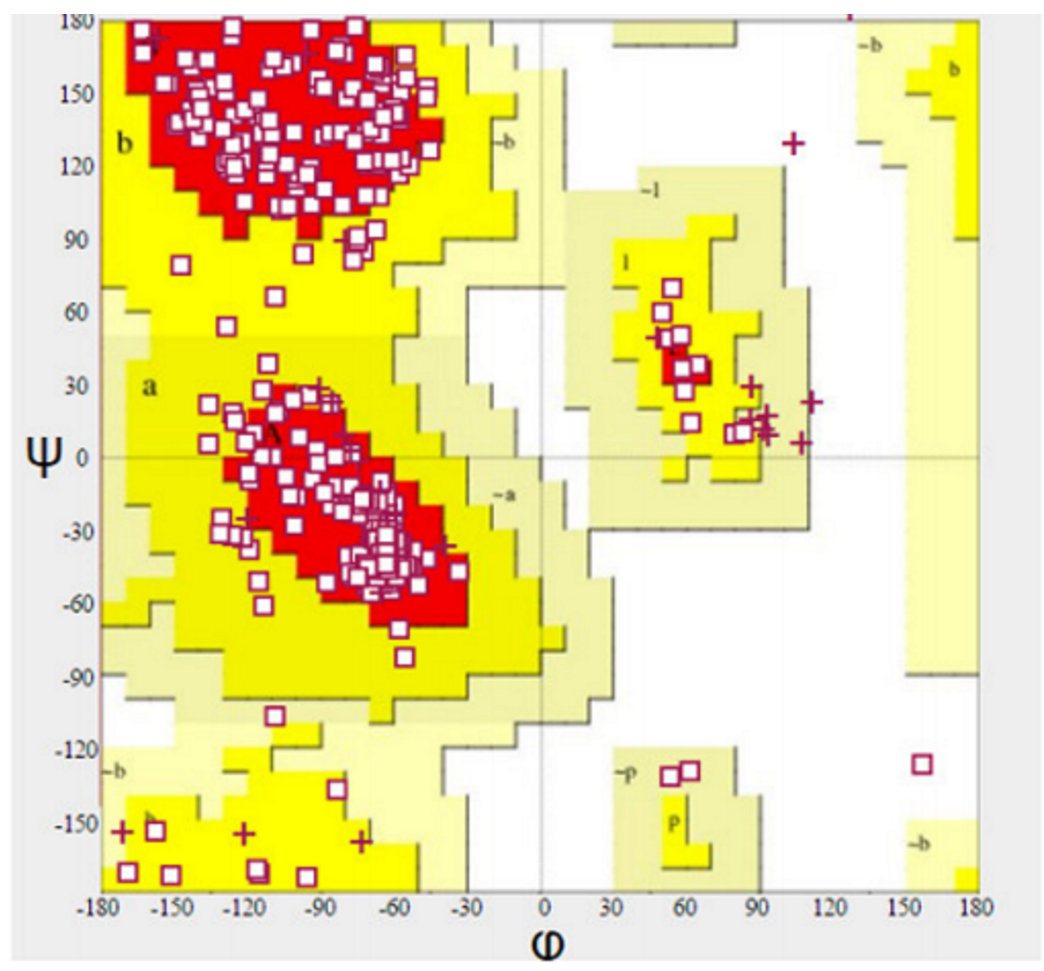

Figure 2. Ramachandran plot of homology modeled protein. 

leads for Oral Squamous Cell Carcinoma 2021;9(06):108-114

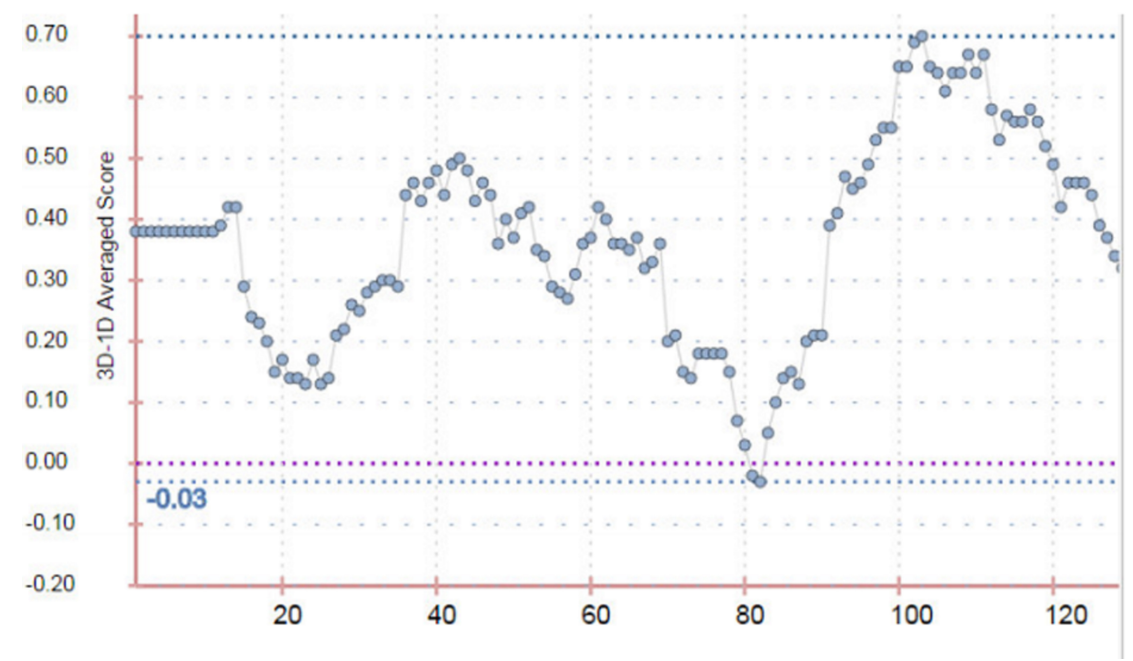

Figure 3. Verify-3D result of homology modeled protein.

the results, the top model was selected (template: 2vqw.1.A; sequence identity: $47.35 \%$ ) and it was further validated by Ramachandran plot and Verify-3D. Figure 1 shows the homology modeled structure of human HDAC6 as visualized in Chimera version 1.11.1 [31].

In the Ramachandran plot (Figure 2), 93.6\% of the residues were in the favored region, $5.6 \%$ were in allowed region, and $0.8 \%$ was in outlier region, thus showing that it is a reliable structure. From Verify-3D result (Figure 3), it was known that $88.67 \%$ of the residue had an average 3D-1D score of 0.2 , which again showed that the structure is good. A minimum of $80 \%$ of the amino acids must have a score of 0.2 in the 3D/1D profile of Verify-3D, which in this case was satisfied.

\subsection{Virtual Screening and Docking}

Out of 705 phytochemicals that satisfied Lipinski rule of 5, 29 of them were excluded as they were duplicate entries. Finally, docking was carried out for the remaining 676 compounds. Their structures were downloaded in 3D structure data file (SDF format) from PubChem database [32] and were subjected to docking using AutoDock Vina in PyRx 0.8 in order to find optimal conformation of ligands and to understand the nature of interactions between them. Both receptor and ligand files were prepared in accordance with the format required by PyRx 0.8. Based upon the least binding affinity, the best pose was selected and the docked structures were visualized in PyMOL for detailed receptor-ligand interactions. The binding energy of all the docked complexes is given in Table 1.

Figure 4 shows the protein-ligand complex between Camptothecin and homology modeled protein.

From virtual screening results, it was observed that Subtrifloralactone A, Subtrifloralactone B, Subtrifloralactone E, Diosgenin, Inophyllum E, Alpha-Naphthoflavone, Taiwanin C, Subtrifloralactone F, Philadelphicalactone A, Subtrifloralactone C,
Subtrifloralactone D, Remangilones C, Zhankuic acid C, Limonin, Tomatidenol, Withaphysacarpin, Subtrifloralactone G, 4-beta ,7beta, 20R-trihydroxy-1-oxowitha-2,5-dien-22,26-olide, Diosmin, Silymarin, Sanguinarine, Taiwanin E, Cycloartobiloxanthone, Remangilones A, Tubulosine, Galbacin, Farnesiferol C, Withaferin $\mathrm{A}$, and Camptothecin showed better binding energy (greater than $-6.0 \mathrm{kcal} / \mathrm{mol}$ of the reference compound), thus signifying that these compounds can be potential HDAC6 inhibitors as well as potential drug candidates for OSCC.

\subsection{Cell Line Study}

To verify the possible anti-cancer effect of Camptothecin on oral squamous carcinoma cells, the sample was checked for its capability to inhibit cell growth on SCC-9 cancer cell lines with MTT assay at different concentrations of $0,15,31,62,125,250$, 500 , and $100 \mu \mathrm{g} / \mathrm{ml}$. Proliferation of these cells was significantly inhibited in a concentration-dependent manner for 24 hours, as shown in Figure 5. Camptothecin showed dose-dependent inhibition $(60 \%)$ of the growth of SCC-9 cells at $1 \mu \mathrm{M}$ and $\mathrm{IC}_{50}$ value of $179 \mathrm{nM}$ was obtained (Table 2).

Various studies have reported that Diosgenin inhibits cell proliferation and induces apoptosis in various human tumor cells such as prostate, breast, liver, colon, leukemia, and osteosarcoma $[33,34]$. Although anti-cancer properties and pro-apoptotic effect of Diosgenin are reported in various studies, its effect on squamous cell carcinomas alone is not yet fully studied [35]. In this study, Diosgenin, exhibited $37 \%$ inhibition at $400 \mu \mathrm{M}$ concentration on the SCC-9 cell line (Table 3).

Therefore, this study demonstrated the anti-cancer activity of Camptothecin and Diosgenin against SCC-9 cell lines, thus validating its inhibitory activity experimentally and indicating that it can be a potential inhibitor for Oral Cancer. In addition, remaining hits can be further examined for their anti-proliferative effects on Oral Cancer cells. 
Table 1. Top hits resulted from docking.

\begin{tabular}{|c|c|c|c|}
\hline $\begin{array}{l}\text { SI } \\
\text { No. }\end{array}$ & Compound & PubChem ID & $\begin{array}{c}\text { Binding energy } \\
\text { (kcal/mol) }\end{array}$ \\
\hline 1 & Subtrifloralactone A & 10928536 & -8.9 \\
\hline 2 & Subtrifloralactone B & 10906541 & -8.9 \\
\hline 3 & Subtrifloralactone E & 21600009 & -8.6 \\
\hline 4 & Diosgenin & 99474 & -8.5 \\
\hline 5 & Inophyllum E & 455251 & -8.3 \\
\hline 6 & Alpha-Naphthoflavone & 11790 & -8.2 \\
\hline 7 & Taiwanin C & 363127 & -8.2 \\
\hline 8 & Subtrifloralactone F & 21600010 & -8.2 \\
\hline 9 & Philadelphicalactone A & 11038269 & -8.1 \\
\hline 10 & Subtrifloralactone C & 11027076 & -8 \\
\hline 11 & Subtrifloralactone D & 21600008 & -8 \\
\hline 12 & Remangilones C & 397856 & -7.9 \\
\hline 13 & Zhankuic acid C & 10838646 & -7.9 \\
\hline 14 & Limonin & 179651 & -7.9 \\
\hline 15 & Tomatidenol & 6453043 & -7.9 \\
\hline 16 & Withaphysacarpin & 44567005 & -7.9 \\
\hline 17 & Subtrifloralactone G & 21600011 & -7.9 \\
\hline 18 & $\begin{array}{c}\text { 4-beta, 7-beta, } \\
\text { 20R-trihydroxy-1- } \\
\text { oxowitha-2,5-dien-22,26- } \\
\text { olide }\end{array}$ & 10950818 & -7.9 \\
\hline 19 & Diosmin & 5281613 & -7.8 \\
\hline 20 & Silymarin & 1548994 & -7.8 \\
\hline 21 & Sanguinarine & 5154 & -7.8 \\
\hline 22 & Taiwanin E & 493164 & -7.8 \\
\hline 23 & Cycloartobiloxanthone & 10342859 & -7.8 \\
\hline 24 & Remangilones A & 10503181 & -7.7 \\
\hline 25 & Tubulosine & 72341 & -7.7 \\
\hline 26 & Galbacin & 234441 & -7.7 \\
\hline 27 & Farnesiferol C & 11090246 & -7.7 \\
\hline 28 & Withaferin A & 265237 & -7.6 \\
\hline 29 & Camptothecin & 24360 & -7.5 \\
\hline 30 & Vorinostat $^{\mathrm{a}}$ & 6918638 & -6.0 \\
\hline
\end{tabular}

Reference compound is indicated by 'a'.

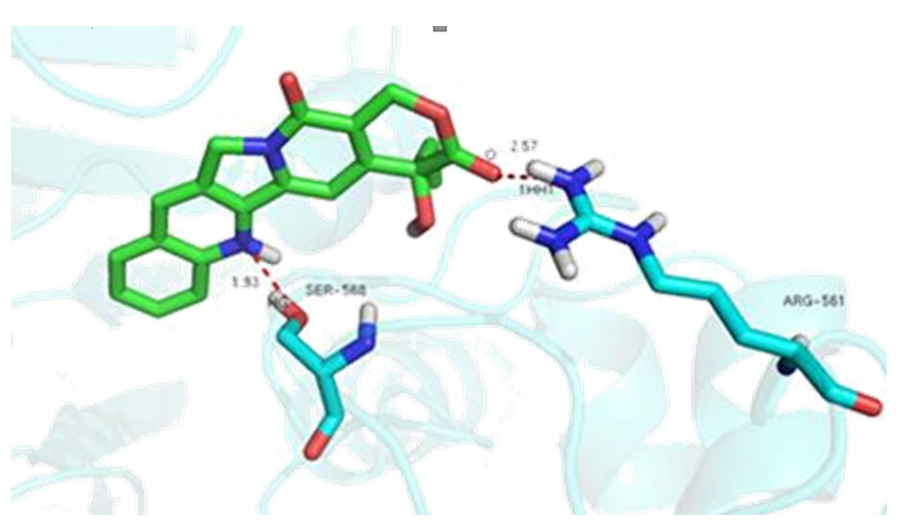

Figure 4. Docked complex of Camptothecin with homology modeled protein.

\section{Effect of Camptothecin in SCC-9}

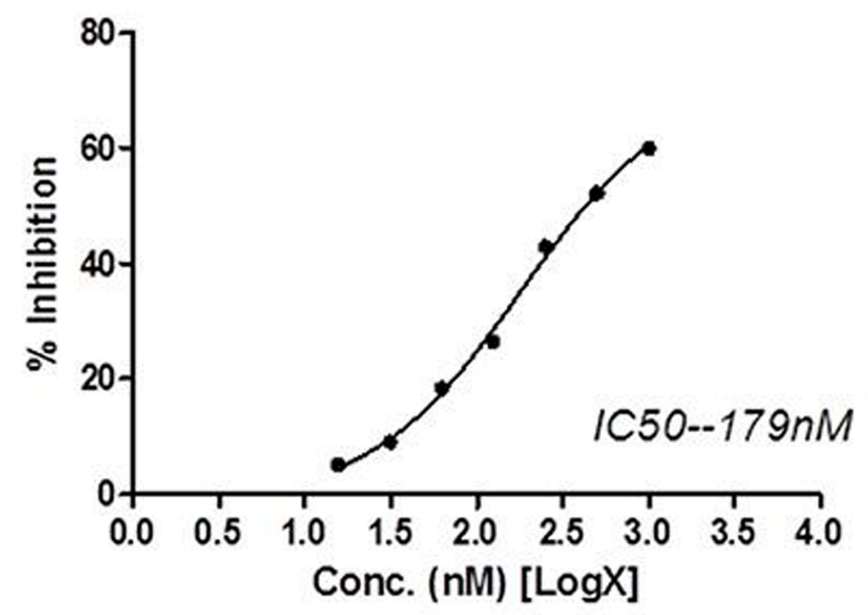

Figure 5. Dose-response curve.

Table 2. Camptothecin result on SCC-9 cell line.

\begin{tabular}{cccc} 
Sample name & $\begin{array}{c}\text { Conc. } \\
(\mathbf{n M})\end{array}$ & $\begin{array}{c}\text { OD at 590 } \\
\mathbf{n m}\end{array}$ & \% Inhibition \\
\hline Control & 0.529 & 0.00 \\
& 15.6 & 0.502 & 5.12 \\
Camptothecin & 31.3 & 0.481 & 9.09 \\
& 62.5 & 0.432 & 18.40 \\
& 125.0 & 0.389 & 26.52 \\
& 250.0 & 0.302 & 42.95 \\
& 500.0 & 0.253 & 52.21 \\
& 1000.0 & 0.212 & 59.95 \\
\hline
\end{tabular}

Table 3. Diosgenin result on SCC-9 cell line.

\begin{tabular}{cccc} 
Sample name & Conc. $\boldsymbol{\mu M}$ & $\begin{array}{c}\text { OD at 590 } \\
\mathbf{n m}\end{array}$ & \% Inhibition \\
& Control & 0.529 & 0.00 \\
\multirow{4}{*}{ Diosgenin } & 6.25 & 0.514 & 2.91 \\
& 12.5 & 0.504 & 4.74 \\
& 25 & 0.475 & 10.20 \\
& 50 & 0.464 & 12.35 \\
& 100 & 0.457 & 13.68 \\
& 200 & 0.356 & 32.75 \\
& 400 & 0.334 & 36.91 \\
\hline
\end{tabular}

\section{CONCLUSION}

From virtual screening results, it was observed that Subtrifloralactone A, Subtrifloralactone B, Subtrifloralactone E, Diosgenin, Inophyllum E, Alpha-Naphthoflavone, Taiwanin C, Subtrifloralactone F, Philadelphicalactone A, Subtrifloralactone C, Subtrifloralactone D, Remangilones C, Zhankuic acid C, Limonin, Tomatidenol, Withaphysacarpin, Subtrifloralactone G, 4-beta ,7- 
beta ,20R-trihydroxy-1-oxowitha-2,5-dien-22,26-olide, Diosmin, Silymarin, Sanguinarine, Taiwanin E, Cycloartobiloxanthone, Remangilones A, Tubulosine, Galbacin, Farnesiferol C, Withaferin $\mathrm{A}$, and Camptothecin showed better binding energy (greater than $-6.0 \mathrm{kcal} / \mathrm{mol}$ of the reference compound), thus signifying that these compounds can be potential HDAC6 inhibitors as well as potential drug candidates for OSCC. Also, hits namely Camptothecin and Diosgenin showed inhibitory activity against SCC-9 cell lines, thus indicating that it could be a potential drug candidate for Oral Cancer.

\section{ACKNOWLEDGMENTS}

The authors sincerely acknowledge Skanda Life Sciences Pvt. Ltd., Bangalore, and Department of Biotechnology, PESIT, Bangalore, for their support.

\section{AUTHOR CONTRIBUTIONS}

All authors made substantial contributions to conception and design, acquisition of data, or analysis and interpretation of data; took part in drafting the article or revising it critically for important intellectual content; agreed to submit to the current journal; gave final approval of the version to be published; and agree to be accountable for all aspects of the work. All the authors are eligible to be an author as per the international committee of medical journal editors (ICMJE) requirements/guidelines.

\section{FUNDING}

There is no funding to report.

\section{CONFLICT OF INTEREST}

No conflicts of interest.

\section{ETHICAL APPROVALS}

This study does not involve experiments on animals or human subjects.

\section{REFERENCES}

1. Cheng T, Li Q, Zhou Z, Wang Y, Bryant SH. Structure-based virtual screening for drug discovery: a problem-centric review. AAPS J 2012;14:133-41.

2. Maria Antony Dhivyan JE, Anoop MN. Virtual screening and lead optimization to identify novel inhibitors for HDAC-8. arXiv, Cornell University, New York, pp 1-58, 2012.

3. Warren GL, Andrews CW, Capelli AM, Clarke B, LaLonde J, Lambert $\mathrm{MH}$ et al. A critical assessment of docking programs and scoring functions. J Med Chem 2006;49:5912.

4. Monika, Kour J, Singh K. Virtual screening using the ligand ZINC database for novel lipoxygenase-3 inhibitors. Bioinformation 2013;9:583-87.

5. Scully C, Bagan JV. Recent advances in Oral Oncology. Oral Oncol 2007;43:107-15.

6. Coelho KR. Challenges of the oral cancer burden in India. J Cancer Epidemiol 2012;2012:701932.

7. Sakuma T, Uzawa K, Onda T, Shiiba M, Yokoe H, Shibahara T et al. Aberrant expression of histone deacetylase 6 in oral squamous cell carcinoma. Int J Oncol 2006;29:117-24.
8. Gasche JA, Goel A. Epigenetic mechanisms in oral carcinogenesis. Future Oncol 2012;8:1407-25.

9. Warnakulasuriya S. Global epidemiology of oral and oropharyngeal cancer. Oral Oncol 2009;45:309-16.

10. Feller L, Lemmer J. Oral squamous cell carcinoma: epidemiology, clinical presentation and treatment. J Cancer Ther 2012;3:263-68.

11. Jairajpuri ZS, Rana S, Hajela A, Jetley S. Toward early diagnosis of oral cancer: diagnostic utility of cytomorphological features, a pilot study. Natl J Maxillofac Surg 2019;10(1):20-6.

12. Leemans CR, Braakhuis BJM, Brakenhoff RH. The molecular biology of head and neck cancer. Nat Rev Cancer 2011;11:9-22.

13. Patil TT, Patil TT, Kowtal PK, Nikam A, Barkume MS, Patil A, et al. Establishment of a tongue squamous cell carcinoma cell line from Indian Gutka Chewer. J Oral Oncol 2014;2014:1-9.

14. Kowalski LP, Carvalho AL, Priante AVM magrin J. Predictive factors for distant metastasis from oral and oropharyngeal squamous cell carcinoma. Oral Oncol 2005;41:534-41.

15. Singab AS, El-Ahmady S, Milad R, Saad S. Kalanchoe thrysiflora Harv. and Kalanchoe marmorata Baker; DNA profiling, biological guided fractionation of different extracts; isolation and identification of cytotoxic compounds. J Appl Pharm Sci 2012;2:215-20.

16. Al-Zubaydi SR, Al-Hmdany MA, Raesan SJ. Antibacterial effect of some medicinal plant extracts against some pathogenic bacteria strains. J Duhok Univ 2009;12:244-9.

17. Saad B, Azaizeh H, Said O. Tradition and perspectives of Arab herbal medicine: a review. Evid Based Complement Alternat Med 2005;2:475-79.

18. Manasa GC, Meena Kumari P, Muniyappa N, Nanjappa M. Evaluation of the phytochemical, antiproliferative, antioxidant, antibacterial activities of kalanchoe blossfeldiana leaves. Evaluation of the phytochemical, antiproliferative, antioxidant, antibacterial activities of kalanchoe blossfeldiana leaves. World J Pharm Res 2015;4:120114.

19. Sharma MC, Sharma S. Molecular modelling study of uracil-based hydroxamic acids containing histone deacetylase inhibitors. Arabian J Chem 2019;12(8):2206-15.

20. NCBI Resource Coordinators. Database resources of the National Center for Biotechnology Information. Nucleic Acids Res 2016;44:D7-D19.

21. Waterhouse A, Bertoni M, Bienert S, Studer G, Tauriello G, Gumienny R, et al. SWISS-MODEL: homology modelling of protein structures and complexes. Nucleic Acids Res 2018;46(W1):W296-303.

22. Eisenberg D, Lüthy R, Bowie JU. VERIFY3D: assessment of protein models with three-dimensional profiles. Methods Enzymol 1997;277:396-404.

23. Mangal M, Sagar P, Singh H, Agarwal SM. Evaluation of the phytochemical, antiproliferative, antioxidant, antibacterial activities of kalanchoe blossfeldiana leaves. NPACT: naturally occurring plantbased anti-cancer compound-activity-target database. Nucleic Acids Res 2013;41:D1124-9.

24. Chandra N, Bhagavat R, Sharma E, Sreekanthreddy P, Somasundaram K. Virtual screening, identification and experimental testing of novel inhibitors of PBEF1/Visfatin/NMPRTase for glioma therapy. J Clin Bioinforma 2011;1:5.

25. Zhang P, Jie H, Liu J, Zhang XY, Zhang W, Liu M et al. Studies on substituted thienopyridine carbonitriles as src inhibitors using a comprehensive in silico method. Indian J Pharm Sci 2020;82(2):27081 .

26. Trott O, Alson AJ. AutoDock vina: improving the speed and accuracy of docking with a new scoring function, efficient optimization and multithreading. J Comput Chem 2010;31:455-61.

27. Dallakyan S, Olson AJ. Small-molecule library screening by docking with PyRx. Methods Mol Biol 2015;1263:243-50.

28. Zaveri K, Krishna Chaitanya A, Bhaskar Reddy I. Virtual screening and docking studies of identified potential drug target: polysaccharide deacetylase in Bacillus anthracis. Int Lett Nat Sci 2015;34:70-7. 
29. Hoque M, Dave S, Gupta P, Saleemuddin M. Oleic acid may be the key contributor in the BAMLET induced erythrocyte hemolysis and tumoricidal action. PLoS One 2013;8:e68390.

30. Gonzalez RJ, Tarloff JB. Evaluation of hepatic sub cellular Fractions for Alamar blue and MTT reductase activity. Toxicol In Vitro 2001;15:257-9.

31. Huang CC, Couch GS, Pettersen EF, Ferrin TE. Chimera: an extensible molecular modeling application constructed using standard components. Pac Symp Biocomput 1996;1:724.

32. Bolton E, Wang Y, Thiessen PA, Bryant SH. PubChem: integrated platform of small molecules and biological activities. Annu Rep Comput Chem 2008;4:217-41.

33. Chen PS, Shih YW, Huang HC, Cheng HW. Diosgenin, a steroidal saponin, inhibits migration and invasion of human prostate cancer PC-3 cells by reducing matrix metalloproteinase expression. PLoS One 2011;6:e20164.

34. Li F, Fernandez PP, Rajendran P, Hui KM, Sethi G. Diosgenin, a steroidal saponin, inhibits STAT3 signaling pathway, leading to suppression of proliferation and chemosensitization of human hepatocellular carcinoma cells. Cancer Lett 2010;292:197-207.

35. Das S, Dey KK, Dey G, Pal I, Majumder A, MaitiChoudhury S, et al. Antineoplastic and apoptotic potential of traditional medicines thymoquinone and diosgenin in squamous cell carcinoma. PLoS One 2012;7:e46641

\section{How to cite this article:}

Vijayasarathy S, Chatterjee J. Virtual screening for novel inhibitors of human histone deacetylase 6: Promising new leads for oral squamous cell carcinoma. J Appl Biol Biotech 2021; 9(06):108-114. 